\title{
Managing Protean Diversity
} An Empirical Analysis of How Organizational Contextual Dynamics Derailed and Dissolved Global Workforce Diversity

Marfelt, Mikkel Mouritz; Muhr, Sara Louise

Document Version

Accepted author manuscript

Published in:

International Journal of Cross Cultural Management

DOI:

$10.1177 / 1470595816660120$

Publication date:

2016

License

Unspecified

Citation for published version (APA):

Marfelt, M. M., \& Muhr, S. L. (2016). Managing Protean Diversity: An Empirical Analysis of How Organizational Contextual Dynamics Derailed and Dissolved Global Workforce Diversity. International Journal of Cross Cultural Management, 16(2), 231-251. https://doi.org/10.1177/1470595816660120

Link to publication in CBS Research Portal

\section{General rights}

Copyright and moral rights for the publications made accessible in the public portal are retained by the authors and/or other copyright owners and it is a condition of accessing publications that users recognise and abide by the legal requirements associated with these rights.

\section{Take down policy}

If you believe that this document breaches copyright please contact us (research.lib@cbs.dk) providing details, and we will remove access to the work immediately and investigate your claim. 


\section{Managing Protean Diversity: An Empirical Analysis of How Organizational Contextual Dynamics Derailed and Dissolved Global Workforce Diversity}

\section{Mikkel Mouritz Marfelt and Sara Louise Muhr}

Journal article (Post print version)

CITE: Managing Protean Diversity : An Empirical Analysis of How Organizational Contextual Dynamics Derailed and Dissolved Global Workforce Diversity. / Marfelt, Mikkel Mouritz; Muhr, Sara Louise. In: International Journal of Cross Cultural Management, Vol. 16, №. 2, 2016, p. 231-251.

DOl: 10.1177/1470595816660120

Uploaded to Research@CBS: October 2016 


\title{
Managing protean diversity: An empirical analysis of how organizational contextual dynamics derailed and dissolved global workforce diversity
}

\begin{abstract}
Recently, global workforce diversity and its management have received criticism for not paying attention to the contextual influence stemming from socially constructed dialectics of power and politics. These contextual dynamics, however, tend to be viewed as external to the organization. In this paper, we follow the call for critically investigating the contexts influencing diversity management by analysing the development of a global Human Resource Management (HRM) project initiated to promote a culturally-diverse workforce. We find that despite good intentions, as well as support from top management, the project dissolves through micro-politics and power dynamics. We contribute to the critical literature on workforce diversity by identifying how organizational contextual dynamics influence the way the concept of workforce diversity is constructed and understood at work. Based on these findings, we develop the concept of protean diversity to better understand how to manage the ever-changing and unstable nature of contemporary workforce diversity.
\end{abstract}

\section{Keywords:}

Protean diversity, contextual dynamics, diversity management, HRM practices, power, politics 


\section{Introduction}

Due to increased global mobility and the global expansion of many organizations, most large organizations are in one way or another faced with the task of managing an increasingly diverse and global workforce. Therefore, many of them, especially the larger organizations, engage in diversity management projects that have the purpose of managing and capitalizing on the diverse human resources at their disposal; that is, they strive to optimize the differences to the benefit of organizational goals (Jonsen and Özbilgin, 2014). In parallel with such practical interests, the scholarly fields of both cross-cultural management (CCM) and diversity management (DM) have been concerned with developing models and frameworks for the management of people with diverse backgrounds and profiles (see for example Ely and Thomas, 2001; Ferdman and Brody, 1996).

This managerialist approach to managing diversity in CCM and DM has, however, been criticized by a growing body of literature identifying with what Lorbiecki and Jack (2000) refer to as the critical turn in diversity management that is concerned with deconstructing CCM's reliance on national culture differences as static and DM's focus on differences as comprehensible and manageable. Both CCM and DM have in this way been exposed to the same critique, which proposes that diversity instead of being static rests on local categories defined according to their co-dependence with historical, institutional and socio-economic issues (e.g. Goxe and Paris, 2016; Prasad et al., 2006; Tatli and Özbilgin, 2012). Diversity is therefore socially constructed and per definition dependent on local issues of power, language and politics (Sambajee, 2016; Zanoni and Janssen, 2004), which tend not to be captured in the static approaches of traditional CCM and DM.

However, often coming from the political-ideological focus of critical theory or similar (e.g. Fournier and Grey, 2000), such context-sensitive approaches to managing diversity tend to focus on historical, cross-cultural and societal influences (Gotsis and Kortesi, 2014). Although relevant and important, such a strong focus on external influences has left the organizational level largely unexplored by critical scholars in CCM and DM (Jonsen et al., 2011) - also the relationship between organizational matters and broader layers of influence. This means that most studies at the organizational level are largely dominated by quantitative studies trying to map the effects of diversity initiatives, cross-cultural training programs or similar functionalistic / managerialistic focuses (De Wit et al., 2012; Kalev et al., 2006; Kochan et al., 2003). Here, one argument dominates: Diversity programmes need top-management support in order to 
succeed. If such programmes fall to, for example, HRM or a lower-level diversity manager, they get sidetracked (Agars and Kottke, 2005; Tatli and Alasia, 2011; Williams, 2013).

Our ethnographic, longitudinal case study in an organization known for its progressive diversity initiatives, however, showed that despite top-management support and significant status in the organization, the diversity project that set out to plan the future global workforce needs, still failed. This empirical fact is interesting as it forces us to think about why is it that so many diversity projects fail - despite structural support - and made us curious about what other organizational contextual factors that might have influenced the faith of the diversity project and how these were connected to broader layers of influence as hailed by the critical community. Since we have in-depth empirical data on the way the project developed over time and was indeed constructed through various organizational contextual influences, we saw the possibility of contributing to both CCM and DM with a critical contextual account of such influence. Based on this, the paper aims to discuss the following question:

How does the organizational context influence the way workforce diversity is constructed, understood and thus implemented and practiced in the organization?

In what follows, we analyse how the emergent nature of the concept of workforce diversity is influenced and changed (and in this case dissolved) by organizational contextual dynamics and conclude by suggesting that the concept of protean workforce diversity can help researchers, as well as managers, better understand and manage the emergent nature of contemporary diversity in the implementation of cross-cultural and global workforce diversity initiatives.

\section{Diversity management}

Managing diversity and the literature on it has long been concerned with how employee differences (culturally as well as individually) can be optimized and capitalized on, or at least organized in a way that minimizes conflict and collaboration difficulties (e.g. De Wit et al., 2012; Kalev et al., 2006; Kochan et al., 2003). By promoting the business case for diversity, this particular diversity management view distanced itself from the moral and legal concerns of its predecessors 'affirmative action' and ‘equal employment opportunities', which dominated the late 1960s and early 1970s (Holvino and Kamp, 2009). While a management focus on workforce diversity might give preference to managerial and economic concerns - and as such has gained more attention from businesses than affirmative action and equal employment opportunities - it has been profoundly criticized for overlooking social, cultural and historical 
manifestations of, for example, marginalization, racism, sexism, discrimination and segregation (e.g. Goxe and Paris, 2016; Omanovic, 2009; Tatli and Özbilgin, 2012). Identified as the critical turn of diversity management (Lorbiecki and Jack, 2000), a now sizable body of literature has set out to expose the often hidden dimensions of power influencing diversity management practices (Ghorashi and Sabelis, 2013). However, in order to resist the subjugating power of diversity, the main objective becomes to 'unmask 'hidden' contexts and 'invisible' power relations' (Ahonen et al., 2014: 270) and question established structures of domination and subordination (Meriläinen et al., 2009). Here, it has been argued that because issues of hierarchy, privilege, equity, discrimination and organizational justice are left alone (Holvino and Kamp, 2009; Oswick and Noon, 2014; Tomlinson and Schwabenland, 2010), a systemic oppression ensues. Consequently, rather than leading to greater equality, diversity management practices (by ignoring the socio-historical embeddedness of diversity) are naïve and at times even unethical (Muhr, 2008).

Instead of securing equality or inclusion, many diversity practices seem to reinforce stereotypes and the marginalization of minorities (Ghorashi and Sabelis, 2013). In response, critical researchers are beginning to suggest that we need to 'rethink ... taken-for-granted analytic categories for representing otherness' (Ailon, 2008: 900), arguing for methods that transgress the categories (Muhr, 2008; Rhodes and Westwood, 2007; Janssens and Zanoni, 2014) and binaries (Ahonen et al., 2014; Frenkel and Stenhav, 2006; Muhr and Rehn, 2015) that most diversity initiatives are built on. Therefore, there is little value in using pre-established categories to measure the outcome of diversity. Rather, starting with an exploration of relations of power that lead to the identification of salient categories may yield surprising strands of difference, even though they may leave the researcher in 'unchartered territory' (Tatli and Özbilgin, 2012: 189). The point of, in Tatli and Özbilgin’s (2012) words, an ‘emic approach’ to workforce diversity is to view people's differences as salient and emergent as well as multiple, intersecting and contextual (see also Styhre and Eriksson-Zetterquist, 2008).

\section{Context matters}

Although varying in approach and methodology, a general argument stemming from the above emphasis on a non-categorical or intersectional approach has been that diversity management practices need to be analysed in light of the complexity of shifting and multiple forms of changing situations and contexts within which this practice is performed (Aten et al., 2016; Calás et al., 2013; Jonsen et al., 2011; Holvino and Kamp, 2009; Sambajee, 2016; Tatli 
and Özbilgin, 2012). Critical diversity studies has therefore the past 10 years been devoted to analysing how broader societal discourses on difference influence diversity work and practice, and how diversity is practiced and understood differently in varying national contexts (Holvino and Kamp, 2009).

Here, we find Zanoni and Janssen's (2004) study of HRM managers' discourse about diversity, in which they illustrate how stereotypes in societal discourses influence the way diversity management is practiced. Propelled by this article and its call for a discursive approach, it is now common knowledge in critical diversity management studies that dominant discourses in the socio-cultural context of organizations are of great importance if we are to understand how workforce diversity is understood and performed in the organization.

Difference, it is (correctly) argued, is socially constructed and under constant redefinition due to the influence of competing discourses and existing structures of power (Ahonen et al., 2014; Knoppers et al., 2015; Lorbiecki and Jack, 2000; Van Laer and Janssens, 2011; Zanoni and Janssens, 2004). In order to 'unmask' power dynamics, it is illustrated how diversity management as a managerial practice can be a form of managerial control by defining minority employees in fixed, essential groups with negative connotations (see also Tatli and Özbilgin, 2012a; Ghorashi and Sabelis, 2013; Zanoni et al., 2010; Boogaard and Roggeband 2009; 2000; Simon and Oakes, 2006; Roberson, 2006).

Besides such a broader socio-cultural focus on contexts, which deals with how power discourses influence diversity management, there is also a body of literature that deals with different socio-historical contexts in different national cultures (e.g. Boxenbaum, 2006; Sambajee, 2016; Omanovic, 2009; Romani et al., 2016). Here, Omanovic (2009), for example, discusses diversity management from a dialectical socio-historical perspective where he shows the dependence of diversity management on national translations. The term diversity is often taken for granted and, as a result, many different definitions are used interchangeably without clear definitions (Jonsen et al., 2011). In practice, however, it seems to translate locally due to its various backgrounds. For example, in Scandinavia diversity is deeply intertwined with the development of both the gender equality debate and later the ethnic minority debate (see also Bendl et al., 2016). In the US, for example, it is associated more with race and multi-culturalism (see also Boxenbaum, 2006; Romani et al., 2016). 


\section{Organizational context}

Despite the unquestioned value of the above critical literature, the organizational-level analysis - as proposed by Jonsen et al. (2011) - is highly underrepresented in diversity management research. Typically, it gets attention in relation to top-management involvement and this without a recognition of broader layers of influence. Here, however, it is also heavily and almost unanimously argued that top-level support is crucial for diversity projects specifically (and HRM projects in general) to gain legitimacy and become embedded throughout the organization (Tatli and Alasia, 2011). To do this, management needs to show commitment not only by supporting the project financially but also by promoting the project publicly and participating in diversity workshops. While many critical studies (rightfully and usefully) expose the influences of broader socio-cultural and socio-historical contexts on the practice of diversity management, very few studies adopt an intra-organizational, qualitative and dynamic approach to the study of organizational contexts. It is this gap that we address in this paper and by doing this we contribute to critical debates of DM and CCM by showing how the diversity in the organizational context is also constructed through both micro and macro layers of power and politics. As such, our argument maintains that workforce diversity is not only nationally and culturally situated but also evolves according to its organizational-political situatedness. In this sense, we utilize what we call a micro socio-cultural perspective as we focus on how the local organizational premises of the diversity project influence the way it develops over time.

\section{Methodology}

\section{Research context}

In order to gain rich, robust descriptions at the micro socio-cultural level, the first author of this paper followed a 'Diverse and Global Workforce' project in the Scandinavian technology company PharmaTech (a pseudonym). The first author was employed in PharmaTech as an industrial $\mathrm{PhD}$ fellow. An industrial $\mathrm{PhD}$ spends $50 \%$ of the time in the company (and $50 \%$ at the university) over a three-year period. The doctoral research took place in the corporate HRM division in PharmaTech's corporate headquarters and was centred on the (at that time) new Diverse and Global Workforce project. The author had access to other parts of the company, however, since he took an approach that followed the object (Marcus, 1998) he did not seek accounts beyond the outreach of Diverse and Global Workforce project, but rather sought to let the project team determine the outreach through the development of the project. As will be 
unfolded later in this paper, the Diverse and Global Workforce project eventually did not reach beyond the corporate headquarters, which limits the scope of the study to exclusively providing a corporate perspective on global workforce diversity.

The first author took steps to address the ethical dilemma of both being employed by the company while striving to provide personal and critical accounts of events taken place. While the first author was provided with an almost unrestricted access, he also agreed to ensure a highlevel of anonymity for the participants' involvement. During the writing of this paper a company representative read through the paper. The company representative agreed that anonymity was respected and accepted the current version of the paper with the only other request that company job titles were changed to more generic titles.

All in all, the contractual agreement meant that at no time during these three years did the author completely drop his engagement with PharmaTech. As a consequence, he was kept up to date with developments relating to the Diverse and Global Workforce project - including after the closing down of the Diverse and Global Workforce project. Long-term involvement in the empirical setting therefore came as an automatic part of the contractual setup. During his time in PharmaTech, the first author was included as an employee in the Department of Organizational Development, with all the typical activities associated with this position (such as department meetings, lunches, an office desk space, team building exercises, etc.).

After the closing down of the Diverse and Global Workforce project in January 2013 the first author conducted half a dozen more interviews, which occurred up until the end of his three-year-long industrial PhD fellowship (ending in June 2015). All in all, this long-term ethnographic method provided us with rich data from the organizational context in which the Diverse and Global Workforce project was initiated, developed and terminated. Table 1 summarize the number of recorded observations and interviews done from March 2012 to June 2015. The first author translated all relevant material to English, which has been used as part of the empirical material in this paper.

\section{Observations}

(90-180 minutes)

\section{9}

Total number of recordings
While the majority, 32 recordings, were meetings held with the project team, another 17 of these were workshops including people beyond the team (ranging

\section{Interviews}

(45-120 minutes)
The total number of interviews comprised of about $40 \%$ semi-structured and $60 \%$ unstructured interviews. 


\begin{tabular}{lll}
$\begin{array}{l}\text { Positions held by } \\
\text { informants }\end{array}$ & $\begin{array}{l}\text { Project team members, Senior Vice } \\
\text { Presidents, Vice Presidents, department } \\
\text { managers, common employees, external } \\
\text { consultants, internal consultants }\end{array}$ & $\begin{array}{l}\text { Project team members, corporate } \\
\text { managers, other department managers, } \\
\text { common employees }\end{array}$ \\
Languages & $\begin{array}{l}\text { Workshops were held in English, while } \\
\text { project team meetings were held in the } \\
\text { Scandinavian language spoken by the } \\
\text { majority of PharmaTech employees } \\
\text { (disclosed for anonymity reasons). }\end{array}$ & $\begin{array}{l}\text { With the exception of two interviews in } \\
\text { English, all other interviews were held in } \\
\text { the Scandinavian language spoken by the } \\
\text { majority of PharmaTech employees } \\
\text { (disclosed for anonymity reasons). }\end{array}$ \\
\hline
\end{tabular}

PharmaTech employs more than 40.000 people and estimates a significant expansion in its global workforce in the coming decade to more than 60.000 employees. The company had about 14.000 employees in its Scandinavian headquarter, and expected an increase of about 3.000 people in the headquarters in the coming decade. This meant that a demographical shift would occur since the number of employees outside headquarters would increase more than the number of headquarter-employed employees. This demographical shift was a central to the launch of the Global and Diverse Workforce project.

PharmaTech is a global market leader within its field and has long been known for its progressive diversity policies and practices. In the years preceding the start of this ethnographic case study, PharmaTech was planning to initiate projects focusing on future growth and the challenges associated with predicting and managing the demands of a diverse future workforce. The aim of the Diverse and Global Workforce project was to seek inclusiveness, remain critical of dominant stereotypes, and to rework the organizational approach to the workforce in a manner that accounted for cultural differences among employees. In other words, it resembled a project adhering to the critical spirit of an 'emic' approach where categories were not decided in advance, but were rather allowed to emerge in accordance with the socio-political context of the project.

In line with this, the project team early on listed specific areas of interest, including individual differences, cultural differences and values, as well as the reassessment of organizational processes to better accommodate employee differences. Two central assumptions underpinning the project were:

- The workforce is becoming more diverse due to the future growth, globalization and increased age and generational composition. 
- There is a demand for tailored solutions in order to better meet specific employee needs and so a one-size-fits-all approach to the organizational workforce must be replaced by a one-size-does-not-fit-all approach.

Given that diversity was formulated in such salient and emergent ways, the project represented an ideal opportunity to follow how a diversity management project develops over time - i.e. how workforce diversity translates and transforms in the organization as the project develops.

\section{Data construction}

In order to gain a rich understanding of how the project travelled and developed through the organization, the ethnographic study of the Diverse and Global Workforce project was approached with an open-ended research agenda and a loose theoretical framework, the kind of open approach envisaged by Czarniawska when she argues that:

[F]ieldwork knows no 'method'; it relies on pragmatism, luck, and moral sensibility. The knowledge of a variety of techniques, and the will to innovate rather than follow static prescriptions of method books, remain central to the craft of fieldwork, as to all others. (Czarniawska, 2008b: 10)

'Ethnographic fieldwork' then refers to a style of research rather than a single method - a style that uses a variety of techniques in order to collect empirical material (Brewer, 2000). The goal was to provide an emergent, thick description and explanation of the unfolding content and outcomes of the processes the project team undertook to conceptualise and manage a diverse workforce under the aegis of the Diverse and Global Workforce project. As part of the ethics approval for this project, the first author's identity and interests were declared to all participants. He attended planned meetings and interviews, but also followed his intuition in searching for new sources of information, following interesting occurrences and rephrasing questions as they arose, as well as enjoying serendipitous conversations about unexpected issues (cf. Marcus, 1998). The researcher used participant-observational techniques, conducted formal and informal interviews, and collected documentary materials as part of the ethnographic fieldwork. Over the course of the 10-month data collection period, the first author participated in and observed a set of weekly two-hour project meetings, of which 90\% was audio-recorded (generating about 150 hours of recorded meetings). The first author conducted formal interviews - both unstructured and semi-structured - and numerous other informal individual and group interviews about the 
project. Daily field-note journals were maintained during the study, with the content organized by section to enable iterative analysis and personal reflection.

Considering the constructionist claim that 'no real world out-there (whether it exists or not) can be accounted for objectively by any observer' (Czarniawska, 2008a: 3) points to how no method is neutral. We embrace such a constructionist perspective and instead argue that any method generates, or constructs, the empirical material. In addition, and of equal importance, we recognize that the empirical material constructs any phenomena under investigation. In this view, 'gathering' or 'collecting' empirical data is an imprecise description of what occurred. Simply put, the researcher contributes to the construction of the concept under investigation - in this case 'a diverse and global workforce' - simply by making choices about which methods to use.

An abductive approach recognizes how the researcher constructs the phenomena studied by emphasizing how theory, methodology and empirical material are continuously assessed and constructed (Alvesson and Kärreman, 2011; Alvesson and Sandberg, 2013). Inspired by the promise of research in 'favor of interesting, challenging and novel ideas' (Alvesson and Kärreman, 2011: 75), the first author created what Reichertz refers to as an 'abductive climate' by adopting an 'attitude of preparedness to abandon old convictions and to seek new ones' (Reichertz, 2007: 22). One way to adopt an attitude open to different interpretations was to start mapping and categorizing multiple ways of viewing and interpreting the empirical material. In addition to keeping a logbook in which he wrote personal reflections, the first author kept a 'brainstorming document' in which he wrote down different ways to conceptualize and interpret the case. Five months into the project, this document contained 61 different perspectives. The researcher started revisiting this 'brainstorming document' on a regular basis. While some of these perspectives focused on topics far from the central theme of this paper, several of them centred on the conceptualization of workforce diversity.

\section{Research participants}

The study took place in PharmaTech's global HRM division, an area of work focusing on the provision of global processes that relate to the management of the company's workforce. As will be unfolded below, several stakeholders happened to gain influence over the Diverse and Global Workforce project. In line with the emergent methodology, the informants central to the research were selected based on their hierarchical levels of importance to the project. At the end, these ended up being: 
- Global HRM divisional management consisting of Gareth (Senior Vice President) and Cameron (Executive Vice President).

- $\quad$ The 'Diverse and Global Workforce project team' situated in the global HRM division consisting of the project manager Leia (Team Member 1) and Trevor (Team Member 2).

- Yannis, the Innovation Department Manager.

- $\quad$ Three Department Managers in close proximity to the project; Luke, Padme and Lando.

Below is a figure that shows the hierarchical positions of all informants included in this paper. The informants will be further introduced as they are presented in the analysis.

Figure 1. Informants included in the quotes presented in this paper.

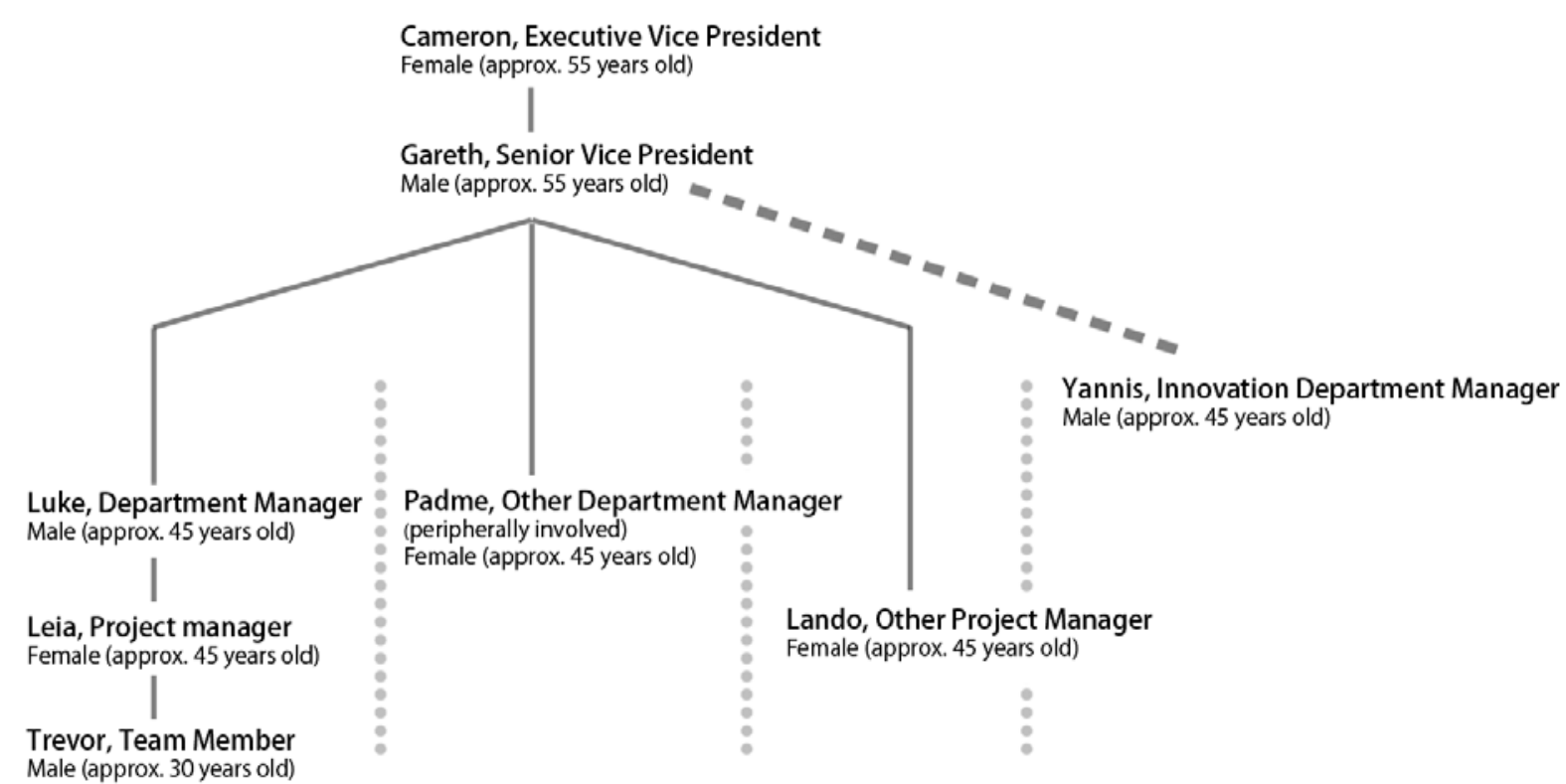

All informants presented in this paper have been given pseudonyms. Moreover, the hierarchical structure portrayed in this paper mimics the structure of the company - though pseudonym job titles have been given to the employees in order to better secure anonymity.

\section{Data analysis}

'Following the project' calls for a narrative approach to data presentation and analysis (Gabriel, 2008). Thus, similar to allowing the unfolding of events to guide the path of data collections, we also construct the narrative of the analysis according to the way the project evolved. In doing so, we did not set out to look for specific organizational contextual dynamics, 
which would potentially influence the project, but instead allowed the process of the project itself to determine which dynamics seemed critical. As such, the analysis provides a narrative account of 'what happened and how this led to that'. Thereby, three key decisions marked significant transpirations in the project, which again influenced the way workforce diversity was constructed and understood in the organization. The three key decisions included: getting economic resources, accommodating to a strategic agenda, and not addressing the 'common employee' (see Figure 2). The foregrounding of these three key decisions over others was derived from the experiences of the ethnographer in the field, the attention eventually given to these decisions - both by project participants and the researcher - as the project unfolded, by the researcher's ongoing and retrospective efforts to make sense of the project, and finally the supporting evidence collected in the process of reviewing notes, interviews and observations. The three central decisions are illustrated below in Figure 2. In the forthcoming analysis, we show how organizational contextual dynamics related to these decisions contributed to the construction of a contextually situated 'workforce diversity'. Our discussion section later in this paper introduces the term 'protean workforce diversity' to point how the concept 'workforce diversity' is a versatile and continuously shifting phenomenon that change according to the context in which it acts. This finding is closely coupled to our methodology, as we seek to trace and portray the changing circumstances around the project, and as we place a focus on both how the project team constructed the concept through key decisions, but also the broader context beyond the control of the project team constructed workforce diversity. We will therefore distinguish between key decisions and contextual dynamics. While key decisions are guided by the people working on the project (i.e. the project team), the 'contextual dynamics' refer to external influences stemming from sources not directly related to the people working on the project and therefore outside the influence of the project team. The central point to make from this is how our methodology and analysis shape our theoretical contribution. Using a narrative construction of the line of events we emphasize differences between different stages of the project, thus constructing the phenomenon under investigation as continuously changing.

Figure 2. The three boxes illustrate the key decisions taken by the Diverse and Global Workforce team.

ATTEMPTS TO GET: MORE RESOURCES (AND ATTENTION)
FOCUSING ON: ACCOMMODATING TO A STRATEGIC AGENDA
LEAVING EARLY ASPIRATIONS: NOT ADDRESSING THE 'COMMON EMPLOYEE' 


\section{Analysis}

Prior to the official launch of the Diverse and Global Workforce project, the global HRM division had an ongoing debate regarding the increasing diversity of the workforce. In this debate, workforce diversification was seen to result from multiple trends, such as the growth in the number of employees, globalization, the introduction of new technologies, and more. At this early stage, interest revolved around exploring future workforce trends, as well as reaching a consensus on the idea that the workforce was in fact becoming increasingly diverse. This led to greater interest in exploring new approaches to the workforce that would enable a more inclusive organizational setup and as such a more diverse workforce. In this early stage and before the project was formally launched, workforce diversity was debated as an open-ended concept in which workforce diversity took the form of a salient and emergent phenomenon influenced by multiple trends, whatever they might be. Here, workforce diversity was not reduced to a set of fixed and dominant social categories and binaries (Ahonen et al., 2014; Frenkel and Stenhav, 2006; Muhr 2008), but was instead open for negotiation and change. Departing from this open-ended representation of workforce diversity, the following analysis will show how the three key decisions shown in Figure 2, changed the way workforce diversity was conceptualized.

\section{$1^{\text {st }}$ key decision: Bringing more economic resources to the project}

\section{Becoming an 'innovation project'}

Though the Diverse and Global Workforce project had been planned since 2009, and the global HRM division was already scoping for an open-ended approach to its diverse workforce, the project was only officially launched in 2012 following a top-level consultancy report done by an external consultancy bureau in 2010. The consultants, otherwise not related to the topmanagement, set to map the challenges and opportunities of ensuring continuous innovation in PharmaTech. The report concluded that, though PharmaTech's core areas (R\&D and production) had a strong culture, the support functions, such as corporate HR, should strengthen their focus on innovation. Concerning the company's innovative capabilities the consultancy report stated:

We believe that [PharmaTech] should connect a small number of initiatives under the headline of innovation, and pursue them in a coordinated fashion, sponsored individually and collectively by executive management. While we do not think this should be done at a scale that in any way 
disrupts the organization, it is important that executive management takes a clear leadership role with these selected projects.

As a result, PharmaTech’s executive management established the Innovation Project Fund supervised by a newly-established Innovation Department. All departments within PharmaTech could therefore apply for funding and receive extra monetary resources in order to establish an 'innovation project'. The global HRM division had already planned, yet not launched, the Diverse and Global Workforce project and so the opportunity to apply for extra resources came at a convenient time. The global HRM division eventually applied for these extra resources under the aegis of the Innovation Project Fund. Out of 25 applications, five projects were selected, the Diverse and Global Workforce project being one of them. The project was then formally established as a result of a successful application process and a set of employees was assigned to spend time on the project, forming what we refer to as 'the project team', consisting of Leia, Trevor and Luke (see Figure 1).

\section{Receiving executive management attention}

The Diverse and Global Workforce project went from being a conceptual idea of exploring how contemporary workforce trends were making the workforce increasingly diverse, to being accepted as an 'innovation project', and as such becoming formally established and receiving extra funds. Through its selection as an innovation project, the Diverse and Global Workforce project awakened the attention of executive management. In a company that runs thousands of projects, having the attention of executive management leverages such a project into a different league. Moreover, projects are often run on tight budgets, therefore additional resources would open up new opportunities.

It all originated from the [consultancy report] pointing out that we could use an innovative culture, also beyond R\&D. In [the global HRM division] that process was driven by a desire for every [Senior Vice President area] to provide an 'innovation project'. At the same time [the project] matched an internal need in [the global HRM division] for understanding future trends. So it was sort of a win-win. We had this idea already, and we might as well try to have it financed by executive management. (Leia, Project Manager) 
Considering top management interpreted ‘innovation’ broadly, quite a few projects could fit comfortably within this term. It was, however, questionable whether this was in fact a clear-cut ‘innovation’ project:

Innovation was a box that encapsulated some of this adequately, some of this 'thinking a bit further ahead' and being 'future oriented'. I'm not sure this is the right way to do it, but that was the coupling that eventually was made. And we decided to view [the Diverse and Global workforce project] as an innovation project... We applied for resources and this fitted well into it. (Luke, Department Manager)

Not only does the case we present concern a project set to investigate the challenges of an increasingly diverse workforce with a corporate and global outlook, but the project also had what seemed like a fortunate position in the sense that it was the first of its kind - a global diversity project - to receive extended attention from executive management. Furthermore, the project was mentioned in the annual report - something many project managers desire - but only few get to experience. Early on, the project team was enthusiastic about the extra resources and attention that came along with being labelled an 'innovation project', and this was seen as positive for the development of the project. For example, the team expected that some of the resources could be directed at interviews with and surveys of those 'common employees" outside corporate headquarters in order to gain a better understanding of the state of the workforce in different parts of the organization - what we refer to as an employee-centric focus. In the following section, we unfold how the focus shifted from this employee-centric focus, to a more top-management and strategic oriented focus and discuss the consequences that this change had on the way workforce diversity was conceptualized.

\section{Change of governance structure}

Prior to becoming one of the five selected innovation projects, the Diverse and Global Workforce project was intended to be a small-scale project governed only by the global HRM divisional management. The transformation into an 'innovation project', however, had radical consequences. For one the governance structure was changed seeing as both the global HRM division and the newly established Innovation Department would have to supervise the project. The introduction of the Innovation Department and the resulting two governing bodies meant that the project was entering into new territory. Each body had their respective agendas and expectations of how the project should be run and what the outcome should be. The main 
concern of Yannis, the manager of the Innovation Department, was to develop and test an Innovation Process Model - an approach to doing innovation that would discipline the act of innovating and reduce it to a series of steps to follow - that (hopefully) would lead to innovative outcomes. Both Gareth, the global HRM division’s Senior Vice President, and Cameron, the Executive Vice President, were concerned with ensuring that the project delivered relevant inputs to executive management now that it had received such extraordinary attention. This implied that the Diverse and Global Workforce project was being assessed on its relevance to executive management.

\section{$2^{\text {nd }}$ key decision: Workforce diversity accommodating to a strategic agenda}

As the project came under executive management's spotlight, other trending topics among top management were integrated into the project; for example, talent attraction, performance and the age-dispersion within the workforce turned out to be integral parts of the project agenda. What started out as an interest in exploring the consequences of changing workforce demographics and assessing broader societal workforce trends took a different turn. The project changed its aspirations by shifting its focus to attracting talent, improving employee performance and addressing the increased life expectancy among employees - in particular how to deal with late career employees who were high performing and wanted to stay in their jobs (such as late career executive managers).

Broadening the scope of the project to include other topics also had consequences for the way workforce diversity was conceptualized. For example, the focus on performance and talent attraction was illustrated through the ways in which the team conceptualized the employee prototype of a young high-performing male and subsequently presented this prototype as a facilitator for discussions at workshops. Moreover, the focus on increased life expectancy among the workforce meant that age became a dominant signifier in conceptualizing workforce diversity. The concept of workforce diversity changed from being open-ended, unspecified, focused on workforce trends and the investigation of changes in the organizations workforce demographics, to being reduced to specific management-directed characteristics; that is, it became a phenomenon to help address issues around talent attraction, employee performance and the increased life expectancy of employees. 


\section{$3^{\text {rd }}$ key decision: Not addressing the 'common employee'}

\section{Extensive reporting obligations}

Another consequence of increased executive management attention was the requirement of the team to make reports to these executive managers. This turned out to be a critical driver in the $3^{\text {rd }}$ key decision. Gareth, the Senior Vice President, went through these reports prior to their approval. If Gareth required any changes to parts of the reports, the team were obligated to rewrite those parts before they were sent to executive management.

\footnotetext{
Since we were an innovation project, we needed to provide continuous reports and that has taken up massive resources. A good example is the Global Senior Management meeting - you know that yearly meeting for the top 250 employees in all of [the company]. The innovation projects were presented at this meeting and a substantial amount of resources was spent doing this. Even though it was such a short session of 5 to 10 minutes, we spent so much time on this, considering what story we wished to tell, what slides should be presented and so on. We had a lot of meetings with [the global HRM Senior Vice President] and [the Executive Vice President] as [she] was supposed to give a broad intro [to the project]. Looking at it today, I'm thinking there's been so much reporting on this. (Luke, Department Manager)
}

Ironically, the extra monetary resources gained from being framed as an innovation project backfired when extra resources were drained from the project in order to accommodate extensive reporting obligations. Given that extensive periods of time were spent framing and phrasing the reports correctly in order to fit the executive management agenda, the team began viewing executive management attention as having indirect obstructive consequences on the development of the project. No direct reports were given to the CEO or other executive managers; rather many of these reports had to go through Gareth, the global HRM Senior Vice President, Cameron, the Executive Vice President as well as Yannis the Innovation Department manager. According to Trevor, this led to a manipulation of information.

[T]aking innovation projects with a high degree of uncertainty and making them executive management funded and putting them in the Senior Vice President areas, makes for a complete contradiction - having something with a high degree of uncertainty [referring to the innovation projects] and expecting them all to be highly successful. Naturally, they can't, so instead they're manipulated, coordinated, twisted and turned all it can take, in order to live up to that. (Trevor, Team Member) 
Hence, what the project team believed to be the most relevant findings sometimes ended up being 'manipulated, coordinated, twisted and turned' before it was presented - not by the team, but by someone else - to executive management.

The extensive reporting obligations had consequences for how workforce diversity was conceptualized. Instead of having time and money to engage with employees beyond the global HRM division, the team was forced to reduce their outreach in favour of engaging only with departments within the global HRM division. More extensive plans to interview and survey employees beyond the global HRM division were dropped and, instead, smaller scale workshops involving other global HRM departments were initiated. This meant that the employee-centric focus was abandoned, in part to fulfil reporting requirements. Having a broad employee outreach, as initially planned, was expected to point to the many nuances of PharmaTech's diverse workforce, potentially leading to a broad and inclusive conceptualization of workforce diversity. Instead, workforce diversity ended up being defined based on a limited set of inputs guided by management.

\section{Increased managerial control}

As noted above Yannis, the Innovation Department Manager, and Gareth, the global HRM Senior Vice President, had different project expectations, which the team had to accommodate. Over time, however, Gareth took on an even more controlling role by taking over project presentations, what Luke refers to as 'fronting the project' in the quote below.

Sure, I’ve also presented [at committee meetings], but [the global HRM Senior Vice President] has been the one 'fronting' the project. So he's the one to please in many ways, and this has been... From one viewpoint this has been an advantage, but from another this has been a disadvantage, because the project was focusing too much on [pleasing the Senior Vice President] - and not so much on what the common employee or the Centre's of Excellence needed. I think we did sort of the same when we worked with diversity, back when we did the first diversity strategy in 20072008. There was a great focus on [the Executive Vice President] and [the global HRM Senior Vice President], and that makes it difficult to navigate through. (Luke, Department Manager)

According to one team member, part of the reason why the Senior Vice President and Executive Vice President became so involved was to ensure project success. 
When you have an executive management funded project, but the project does not have direct reporting to executive management, and instead is placed within a divisional management area, the [Senior Vice President] really wants to see this project become a success. And they want to do many things in order to make the project successful, for if it is not a success, there is a very high visibility around it and that goes straight to the top. (Trevor, Team Member)

By taking over presentations, management ensured that what was being presented was in line with what they deemed important to make the project a success. This, however, meant that the team was striving to both comply with the needs of management while also pursuing what they and others deemed a relevant understanding of workforce diversity. More specifically, as a result of top-management concern over the increased number of late-career employees in corporate head quarters, the team was told by management to investigate the age distribution within the workforce. However, the team also held workshops with other departments within the global HRM division. At some of these workshops, people expressed their frustration regarding the dominant focus on age. Consequently, the team simultaneously began developing a set of locally constructed categories called Life Situations. Life Situations were carefully crafted so that they were age independent and therefore could appeal to other actors within the organization. These categories acted as 'counter categories' to the dominant age category.

Age and its counter categories shaped the way workforce diversity was conceptualized. Instead of getting insights from elsewhere in the organization, the characteristics that defined workforce diversity were constructed based on inputs from nearby management and other employees in close proximity to the team (i.e. employees in other departments in the global HRM division). The conceptualization of workforce diversity therefore ended up including categories that appealed to different interests in close geographical and professional proximity. The conflict within the organization left a mark on the conceptualization of workforce diversity in the sense that the categories chosen represented different stances in this conflict. The conceptualization of workforce diversity therefore became a tool to help mediate a conflict between organizational actors.

\section{Workforce diversity as a 'window dressing' concept}

By the end of the project period, the team's view of executive management involvement had changed from one of enthusiasm to one of frustration. Due to minimal interaction with employees outside corporate headquarters, the project team was forced to make weighty 
assumptions regarding the needs of these 'common’ employees. An increasingly critical tone developed as those involved began questioning the actual purpose of the project:

Interviewer: I wonder why a project such as [Diverse and Global Workforce project] is launched... Why are they putting money into this?

Trevor (Team Member): Because it is a prestige window dressing project.

Lando (other Department Manager): That is precisely what it is, a window dressing project.

[Diverse and Global Workforce project] is truly a window dressing project.

Employees within the global HRM division began to perceive the project as a window dressing project and, as such, grew sceptical over the organization's willingness to engage in diversity issues. Consequently, workforce diversity was rendered without any real impact. Moreover, the team members began to engage in discussions not only on possible ways to remove themselves from the project but also on how best to avoid associations with the project.

\section{Discussion}

\section{Challenging and nuancing a dominant belief in workforce diversity research}

In order to understand the dialectical power dynamics of workforce diversity (e.g. Lorbiecki and Jack, 2000; Zanoni and Janssens, 2004), diversity management literature has called for further research on the influence of context. Despite increased - and important - focus on the socio-historical context of diversity, the field of diversity management (DM) as well as cross-cultural management (CCM) continues to display an absence of critical analyses on how organizational-level influences impact the way diversity is perceived, understood, and thus implemented and practised in organizations. By examining the way in which a global diversity initiative was introduced, developed and terminated in a major global Scandinavian organization, this paper takes one step toward addressing this gap.

Major arguments concerning the influence of organizational-level contextual effects on diversity management projects have thus far been confined to a plethora of books and articles that stress the importance of top-level support in various ways (e.g. Agars and Koffte, 2005; Tatli and Alasia, 2011; Williams, 2013). The argument maintains that in order for diversity management to succeed top-level support is crucial, as it creates resources, legitimacy, diffusion 
and broad commitment. In our case, however, it is notable that the 'perfect setup', namely, a workforce diversity project allocated extraordinary economic resources and increased executive management attention, backfired as the project evolved. Here, the automatic tendency of the project managers to seek out executive attention and additional finances resulted in a series of unforeseen events that affected conceptualizations of workforce diversity. This highlights the need to not simply strive for resources and top-managerial involvement, but to also critically assess the context within which such involvement happen.

Contrary to earlier studies that emphasized the lack of critique of managerial practices and subsequent underlying power relations (see for example Zanoni and Janssen (2004), our case shows how an initial positive attitude toward management involvement turned critical and was accompanied by a reconceptualization of workforce diversity as a window-dressing concept. This indicates that despite, and perhaps partly because of, top management support, the diversity initiative lost its connection to the workforce and thereby the interests and opinions of the employees themselves, who were the original 'targets' of the initiative. Due to initial top-level (monetary) support, the project gained legitimacy throughout the organization. However, following the re-labelling of the project as an innovation project, a series of events (for example change of governance structure, increased reporting obligations etc.) unfolded that effectively diverted attention away from global diversity, cultural differences and workforce trends. As a result, the initial notion of 'one-size-does-not-fit-all' - i.e. the un-categorical and bottom-up approach favoured by critical diversity scholars (e.g. Ahonen et al., 2014; Lorbiecki and Jack, 2000; Muhr, 2008) - dissolved, and the project ended up being perceived as a 'windowdressing' project promoting management’s agenda.

The 'easy' interpretation here would centre on a critique of top management's handling of the process and their appropriation of project ownership in a way that forced the team into a more peripheral role. However, such clarifications are not so straightforward in this case. If, in keeping with those who assess how external power discourses influence workforce diversity (e.g. Zanoni and Janssens, 2004), we take a more dialectic approach to power and politics, we detect something else at play. Our perspective foregrounds how power is not only performed through visible direct measures but also through the subtle everyday actions of micro-politics (e.g. Fleming and Spicer, 2014; Thomas and Davies, 2005). Our aim is not to disagree with arguments that favour top-level support, but rather to add to this argument by developing an understanding of how organizational politics influences diversity management initiatives in unforeseen and unpredictable ways. 


\section{The unpredictability of open-ended and emergent workforce diversity}

Top-level support changed the circumstances surrounding the project and initiated a series of events that the project team had no control over. Such changes ended up greatly affecting the way workforce diversity was understood. However, these changes all stemmed from a locallydriven (not top-level) decision to apply for Innovation Project Fund money. The opportunity to receive more economic resources and the accompanying contextual dynamics (see Figure 3) were not seen as unfavourable until it was too late. This finding illustrates the way a conceptualization of workforce diversity can unfold in unpredictable ways, and how this is sometimes attached to a bigger and more important agenda (such as getting resources or managerial attention). Therefore, our case shows that the coupling of the dynamics of the organizational context is crucial for the way workforce diversity is socially constructed and, thereby, how diversity management projects are perceived in organizations. Perhaps, due to the open and emergent approach to workforce diversity adopted by the team, the conceptualization of workforce diversity was particularly susceptible to contextual influences. We do not argue that diversity should be more strictly defined, as this would jeopardize the benefits of an uncategorical approach and reinstate diversity management within the confines of the differencesameness dilemma identified by critical diversity management scholars (e.g. Ghorashi and Sabelis, 2013). However, we argue that in order to manage such an unstable and emergent concept, a greater understanding of this instability and emergence is required. In the following sections we will discuss how workforce diversity acts in, and is shaped by, a specific context. Here we unfold the notion of 'protean diversity' to place a particular focus on how workforce diversity - in the corporate setting that the case represents - is continuously re-conceptualized via negotiations between multiple human and non-human organizational actors.

\section{Workforce diversity as protean}

The adjective 'protean' is derived from the myth of the Greek god of the sea Proteus, who was able to shape change at will (Hall, 2004). 'Protean workforce diversity' points to the versatile and unstable characteristics of the workforce diversity and how the concept is able to take on many forms - even multiple forms in a specific and confined corporate organizational setting. Two decades ago Robert Golembiewski (1995) pointed to the notion 'protean diversity' arguing that diversity is conceptualized through "continuing dialogue between stakeholders" (Golembiewski, 1995, p. 16). While the idea that diversity is a result of continuous negotiations 
between stakeholders became accepted in much DM literature, the notion 'protean diversity' was only briefly mentioned in Golembiewski's book, and remained peripheral to the broader DM debate in the decades to come (see Golembiewski, 1995: Critchley and Marchart, 2004). We wish to revitalize and expand the idea of 'protean diversity'. Compared to Golembiewski's, we place attention on both the influence of human and non-human actors - thus creating a much wider set of premises for understanding workforce diversity as a protean concept. Let us unfold the importance of this expansion.

Proteanism has been debated, albeit scarcely, in other social scientific disciplines, such as the psychology of the self (Lifton, 1999) and career studies (Hall, 1996; Hall, 2004; Briscoe et al., 2006). Hall's (1996) discussion on protean careers has proven helpful to develop a protean perspective and to understand complex power dynamics and the ways in which they influence the concept of workforce diversity. Hall argues that careers are shaped as people and their environment change over time. In Hall's perspective a protean concept is characterized by its fluidity and in particular by its ability to adapt to contextual circumstances (both human and non-human) as they change. Building on Hall we emphasize how, not only human actors (stakeholders) influence and sometimes determine the understanding of workforce diversity, but also emphasize the importance of non-human contextual actors (such as economic resources, reports, and an 'innovation' label). Moreover we wish to stress how both humans and other nonhuman contextual actors contribute to the conceptualization of workforce diversity. Our particular understanding of 'protean diversity' thus focuses on the complex environment in which both human and other actors together construct the phenomenon in a corporate organizational setting. While this constitutes a new contribution to workforce diversity research there are existing studies that point in a similar direction. Omanović (2009) notes how different actors and milieus, and their often-conflicting ideas and interests, shape diversity and its management. He points to the socio-historical relationships that reflect diversity's on-going productions. Our paper contributes to such a dialectical perspective on workforce diversity by showing how attempts to conceptualize workforce diversity change as a set of contextual dynamics influence the concept.

Our notion of 'protean diversity' has implications for the way we think about workforce diversity. If viewed in terms of our case, we find that workforce diversity evolves according to changes in the surrounding environment. We thus seek to re-introduce the term 'protean' into workforce diversity research to emphasize the changing and versatile nature of the workforce diversity concept, as exemplified by the case presented in this paper. As argued by several 
scholars (see for example Ailon-Sounday and Kunda, 2003; Ellis, 1994; Muhr and Salem, 2013; Rynes and Rosen, 1995), the context in which a diversity project is situated have the ability to not only marginalize and stereotype people but also dissolve and evaporate the understanding of differences and diversity. This in turn renders such concepts empty - i.e. ends up being perceived merely as window-dressing. It is not only the stereotypes that prevent diversity projects from succeeding (Ailon-Sounday and Kunda, 2003), it is also the politics and power of the organization itself that plays a crucial role in how workforce diversity is constructed. Recognizing workforce diversity as protean has consequences for the way we address workforce diversity issues in organizations. To engage with such locally situated, versatile and continuously evolving concept researchers as well as practitioners are required to assess the influence of contextual dynamics. By paying attention to how organizational context interact with workforce diversity we can become attentive to strategic agendas. Ahonen et al. (2014) argue that acknowledging the importance of context as a component of power relations is key to unmasking the ways in which power functions in the production of diversity. We have shown how organizational context matters to workforce diversity - that is, it becomes a shape-shifting concept rather than one guided by aspirations to change conditions for employees. This deterioration accentuates the need to recognize the effects of contextual dynamics on the concept of workforce diversity.

Moreover, our case raises a pertinent concern for future research when it comes to openended and un-categorical approaches to workforce diversity. Are open-ended and vaguely defined workforce diversity approaches at greater risk of acting protean? Do these approaches too easily adapt to the context in which they act? As our case indicates, such an open-ended approach can become problematic when unintended contextual dynamics take control of the project, thereby 'pulling' the project, and as such the conceptualization of workforce diversity, in unintentional and sometimes unfortunate directions.

\section{Conclusion}

We have shown how an open-ended and emergent approach to workforce diversity makes the concept ecologically assembled in combination with its surrounding contextual dynamics in other words how workforce diversity acts protean. These findings point to the need for workforce diversity research to adopt a broader and more situated perspective on diverse workforces in organizations, as opposed to one that narrows in on diversity in any given workforce. Workforce diversity is not simply a matter of difference within the workforce, it is a 
protean concept linked to other dynamics, which, at first glance, might seem unrelated. Moreover, the findings emphasize the importance of not only studying how organizations overcome diversity issues, but also the way organizations construct workforce diversity issues they seek to tackle. Typically, workforce diversity projects are initiated due to either the lack or the increase of diversity in an organization; for example, an overrepresentation of males in management, an increase in the number of employees within an organization, or the inclusion of new geographical regions or proficiencies. However, as shown in this paper, workforce diversity can be a protean concept that easily adapts to new agendas as well as a concept that is at risk of deteriorating into evasive conceptualizations. Put in other words, it is not the differences among people (i.e. the demarcations drawn to delineate workforce diversity) that should claim centrality in diverse workforce research, but rather the ways in which the notion is produced, presented and negotiated in a given context.

The case of the Diverse and Global Workforce project is not unique in the sense that it is not uncommon that diversity projects, and other 'philanthropic' initiatives, sometimes risk benefitting the corporate image rather than making actual changes to the way business is conducted. However, what is rare about this case is the access provided by the company PharmaTech. Following the progression of the Diverse and Global Workforce project has provided rare insights into the initial design phase of such a diversity project - in which dominating diversity traits are under negotiation - from a top-level corporate perspective. As scholars, we require these critical investigations into corporate and top-level politics if we are to understand how these diversity projects can combat political manoeuvrings, manipulation and window dressing. The honest and open account of the 'behind the scenes' events presented in this paper are an important lesson in why some diversity projects fail, or worse, why these projects are 'successful' despite not being so in the eyes of some of the employees closest to the projects.

The findings in this paper illustrate a final key point. If diversity is protean, then we as researchers need to ask ourselves: 'How do we produce diversity?' (Ahonen et al., 2014). Contextual dynamics are not simply elements that exist beyond the influence of those studying them. Rather, researchers situate workforce diversity within a particular context, and the exploration of this situatedness is an equally relevant object of study (see for example Ahonen et al. 2014, Zanoni, et al 2010; Lorbeicki and Jack, 2000). Studying research- and practice-based contextual dynamics enables us to preserve the versatility and changing nature of workforce 
diversity, instead of stabilizing and normalizing the concept through fixation, categorization and taxonomy (Ahonen et al., 2014).

\section{References}

Agars, M., \& Kottke, J. (2006). Innovations in diversity management: Advancement of practice and thought. In R. J. Burke \& C. L. Cooper (Eds.), Reinventing HRM: challenges and new directions (pp. 151-170). Routledge.

Ahonen, P., Tienari, J., Meriläinen, S., \& Pullen, A. (2014). Hidden contexts and invisible power relations: A Foucauldian reading of diversity research. Human Relations, 67(3), 263-286.

Ailon, G. (2008). Mirror, mirror on the wall: Culture's consequences in a value test of its own design. Academy of Management Review, 33(4), 885-904.

Ailon-Souday, G., \& Kunda, G. (2003). The local selves of global workers: The social construction of national identity in the face of organizational globalization. Organization Studies, 24(7), 1073-1096.

Alvesson, M., \& Kärreman, D. (2011). Qualitative Research and Theory Development: Mysteries as Method. London, England: Sage.

Alvesson, M., \& Sandberg, J. (2013). Constructing research questions: Doing interesting research. Sage.

Aten et al., (2016) Making sense of foreign contexts: Skilled migrants’ perception of contextual barriers and career options. International Journal of Cross Cultural Management. In print.

Bendl et al., (2016) Executive search as ethnosociality: A cross-cultural comparison.

International Journal of Cross Cultural Management. In print.

Boogaard, B., \& Roggeband, C. (2010). Paradoxes of Intersectionality: Theorizing Inequality in the Dutch Police Force through Structure and Agency. Organization, 17(1), 53-75. http://doi.org/Article

Boxenbaum, E. (2006). Lost in Translation: The Making of Danish Diversity Management. American Behavioral Scientist, 49(7), 939-948.

Brewer, J. (2000). Ethnography. Buckingham: Open University Press.

Briscoe, J. P., Hall, D. T., \& DeMuth, R. L. F. (2006). Protean and boundaryless careers: An empirical exploration. Journal of Vocational Behavior, 69(1), 30-47. 
Calás, M. B., Ou, H., \& Smircich, L. (2013). “Woman” on the move: Mobile subjectivities after intersectionality. Equality, Diversity and Inclusion: An International Journal, 32(8), 708-731.

Critchley, S., \& Marchart, O. (2004). Laclau: a critical reader. Psychology Press.

Czarniawska, B. (2008a). A Theory of Organizing. Edward Elgar Publishing.

Czarniawska, B. (2008b). Organizing: How to study it and how to write about it. Qualitative Research in Organizations and Management: An International Journal, 3(1), 4-20.

De Wit, F. R., Greer, L. L., \& Jehn, K. A. (2012). A meta-analysis of the relationships between diversity, conflict, and team performance. Journal of Applied Psychology, 92(2), 360390.

Ellis, C. (1994). Diverse approaches to managing diversity. Human Resource Management, 33(1), 79-109.

Ely, R. J., \& Thomas, D. A. (2001). Cultural diversity at work: The effects of diversity perspectives on work group processes and outcomes. Administrative Science Quarterly, 46(2), 229-273.

Ferdman, B. M., \& Brody, S. E. (1996). Models of diversity training. In D. Landis \& R. Bhagat (Eds.), Handbook of intercultural training (Vol. 2, pp. 282-303). Thousand Oaks, CA: Sage.

Fleming, P., \& Spicer, A. (2014). Power in management and organization science. The Academy of Management Annals, 8(1), 237-298.

Fournier, V., \& Grey, C. (2000). At the critical moment: Conditions and prospects for critical management studies. Human Relations, 53(1), 7-32.

Frenkel, M., \& Shenhav, Y. (2006). From binarism back to hybridity: A postcolonial reading of management and organization studies. Organization Studies, 27(6), 855-876.

Gabriel, Y. (2008). Organizing words: A critical thesaurus for social and organization studies. Oxford University Press.

Ghorashi, H., \& Sabelis, I. (2013). Juggling difference and sameness: Rethinking strategies for diversity in organizations. Scandinavian Journal of Management, 29(1), 78-86.

Golembiewski, R. T. (1995). Managing diversity in organizations. University of Alabama Press. Gotsis, G., \& Kortezi, Z. (2014). Critical Studies in Diversity Management Literature: A Review and Synthesis. London: Springer.

Goxe and Paris, 2016 Traveling through the class ceiling? Social mobility of "traditional” and “new” expatriates. International Journal of Cross Cultural Management. In print. 
Hall, D. T. (1996). Protean careers of the 21st century. The Academy of Management Executive, 10(4), 8-16.

Hall, D. T. (2004). The protean career: A quarter-century journey. Journal of Vocational Behavior, 65(1), 1-13.

Holvino, E., \& Kamp, A. (2009). Diversity management: Are we moving in the right direction? Reflections from both sides of the North Atlantic. Scandinavian Journal of Management, 25(4), 395-403.

Janssens, M., \& Zanoni, P. (2014). Alternative diversity management: Organizational practices fostering ethnic equality at work. Scandinavian Journal of Management, 30(3), 317-331.

Jonsen, K., Maznevski, M. L., \& Schneider, S. C. (2011). Special review article: Diversity and its not so diverse literature: An international perspective. International Journal of Cross Cultural Management, 11(1), 35-62.

Jonsen, K., \& Özbilgin, M. (2014). Models of Global Diversity Management. In B. Ferdman \& B. Deane (Eds.), Diversity at work: the practice of inclusion (pp. 364-390). San Fransisco: Jossey-Bass.

Kalev, A., Dobbin, F., \& Kelly, E. (2006). Best practices or best guesses? Assessing the efficacy of corporate affirmative action and diversity policies. American Sociological Review, 71(4), 589-617.

Knoppers, A., Claringbould, I., \& Dortants, M. (2015). Discursive managerial practices of diversity and homogeneity. Journal of Gender Studies, 24(3), 259-274.

Kochan, T., Bezrukova, K., Ely, R., Jackson, S., Joshi, A., Jehn, K., ... Thomas, D. (2003). The effects of diversity on business performance: Report of the diversity research network. Human Resource Management, 42(1), 3-21.

Lorbeicki, \& Jack, G. (2000). Critical Turns in the Evolution of Diversity Management. British Journal of Management, 11, 17-31.

Marcus, G. E. (1998). Ethnography through thick and thin. Princeton University Press.

Meriläinen, S., Tienari, J., Katila, S., \& Benschop, Y. (2009). Diversity management versus gender equality: The Finnish case. Canadian Journal of Administrative Sciences, 26(3), 230-243.

Muhr, S. L. (2008). Othering diversity-a Levinasian analysis of diversity management. International Journal of Management Concepts and Philosophy, 3(2), 176-189.

Muhr, S. L., \& Rehn, A. (2015). On Gendered Technologies and Cyborg Writing. Gender, Work \& Organization, 22(2), 129-138. 
Muhr, S. L., \& Salem, A. (2013). Specters of colonialism-illusionary equality and the forgetting of history in a Swedish organization. Management \& Organizational History, 8(1), 6276.

Omanovic, V. (2009). Diversity and its management as a dialectical process: Encountering Sweden and the U.S. Scandinavian Journal of Management, 25, 352-362.

Oswick, C., \& Noon, M. (2014). Discourses of diversity, equality and inclusion: trenchant formulations or transient fashions? British Journal of Management, 25(1), 23 -39.

Prasad, P., Pringle, J.K., \& Konrad, A.M. (2006). Examining the contours of workplace diversity, in Konrad, A,M, Prasad, P. Pringle, J.K. (Eds.), Handbook of workplace diversity. London: Sage, 1-22.

Reichertz, J. (2007). Abduction: The logic of discovery of grounded theory. Sage.

Rhodes, C., \& Westwood, R. (2007). Letting knowledge go: Ethics and representation of the other in international and cross-cultural management. Business Ethics as Practice: Representation, Reflexivity and Performance, 68-83.

Roberson, Q. M. (2013). The Oxford handbook of diversity and work. Oxford University Press. Rynes, S., \& Rosen, B. (1995). A field survey of factors affecting the adoption and perceived success of diversity training. Personnel Psychology, 48(2), 247-270.

Sambajee, (2016) The dynamics of language and ethnicity in Mauritius. International Journal of Cross Cultural Management. In print.

Simon, B., \& Oakes, P. (2006). Beyond dependence: An identity approach to social power and domination. Human Relations, 59(1), 105-139.

Spradley, J. P. (1979). The ethnographic interview. USA: Harcourt Brace Jovanovich College Publishers.

Styhre, A., \& Eriksson-Zetterquist, U. (2008). Thinking the multiple in gender and diversity studies: examining the concept of intersectionality. Gender in Management: An International Journal, 23(8), 567-582.

Tatli, A., \& Alasia, S. (2011). Resources and constraints of diversity and equality officers: Theoretical and practitioner reflections. In G. Healy, G. Kirton, \& M. Noon (Eds.), Equality, Inequalities and Diversity: Contemporary Challenges and Strategies (pp. 122136). Pelgrave Macmillan: Bassingstoke, UK.

Tatli, A., \& Özbilgin, M. F. (2012). An Emic Approach to Intersectional Study of Diversity at Work: A Bourdieuan Framing. International Journal of Management Reviews, 14(2), 180-200. 
Thomas, R., \& Davies, A. (2005). Theorizing the micro-politics of resistance: New public management and managerial identities in the UK public services. Organization Studies, 26(5), 683-706.

Tomlinson, F., \& Schwabenland, C. (2010). Reconciling competing discourses of diversity? The UK non-profit sector between social justice and the business case. Organization, 17(1), 101-121.

Van Laer, K., \& Janssens, M. (2011). Ethnic minority professionals’ experiences with subtle discrimination in the workplace. Human Relations, 64(9), 1203-1227.

Williams, D. A. (2013). Strategic diversity leadership: Activating change and transformation in higher education. Stylus Publishing, LLC.

Wolcott, H. F. (2005). The art of fieldwork. Rowman Altamira.

Zander, U., Zander, L., Gaffney, S., \& Olsson, J. (2010). Intersectionality as a new perspective in international business research. Scandinavian Journal of Management, 26(4), 457466. http://doi.org/Article

Zanoni, P., \& Janssens, M. (2004). Deconstructing difference: The rhetoric of human resource managers’ diversity discourses. Organization Studies, 25(1), 55-74. 
